\title{
GARANTISMO ESPURIO*
}

\author{
Salazar U., Pedro; Aguiló R., Josep y Presno, Miguel Á., Fundación \\ Coloquio Jurídico Europeo, MAdrid, 2009. 187 pP.
}

J. IGNACIO NúÑEZ LeIVA**

Para los juristas de estirpe latina de uno y otro lado del Atlántico -como certeramente sugiere Alfonso García Figueroa-, en la actualidad, la rúbrica Garantismo se halla vinculada de manera inseparable a la figura de Luigi Ferrajoli. Expuesto en su magna obra Derecho y Razón, desarrollado en un sinnúmero de artículos, comentado por los más destacados jusfilósofos y consolidado en su reciente Principia Juris, propone una doctrina que se proyecta sobre la filosofía jurídica y política e influye en la dogmática constitucional, penal y procesal. ${ }^{1}$

Según el propio jurista de Florencia, mediante el concepto Garantismo se puede aludir a tres nociones distintas, pero vinculadas entre sí. ${ }^{2}$

En primer lugar a un modelo normativo de Derecho, constituido por un sistema de poder mínimo dotado de técnicas de tutela capaces de minimizar la violencia y maximizar la libertad y que en el ámbito jurídico genera un sistema de vínculos impuestos a la potestad punitiva del Estado, apreciable no por su presencia absoluta sino por el grado en que se satisfacen los fines mencionados. En el ámbito constitucional -por ejemplo-se dirá que un sistema es más o menos garantista en tanto cuente con mecanismos de invalidación y reparación idóneos para asegurar la efectividad de los derechos normativamente proclamados.

* Colaboración recibida el 23 de abril y aprobada el 8 de mayo de 2010.

** Abogado; Licenciado en Derecho por la Pontificia Universidad Católica de Chile; Diplomado en Metodologías de Investigación, Universidad Alberto Hurtado y Diplomado en Derechos Humanos, Universidad Católica de Uruguay; Especialista en Constitucionalismo y Garantismo, Universidad de Castilla La Mancha, España; Magíster @ en Derecho Público, Pontificia Universidad Católica de Chile; Doctorando en Derecho, Universidad de Castilla La Mancha, España; Profesor de las facultades de Derecho en las Universidades Alberto Hurtado, Andrés Bello y San Sebastián. Correo electrónico: jinunez@uc.cl.

${ }^{1}$ García Figueroa, Alfonso, "Entrevista a Luigi Ferrajoli", en Carbonel, Miguel; Salazar, Pedro (Edits.), Garantismo: Estudios sobre el pensamiento jurídico de Luigi Ferrajoli, Trotta, Madrid, 2009, p. 515.

${ }^{2}$ En el mismo sentido puede consultarse: Núñez Leiva, José Ignacio, "Un análisis abstracto del Derecho Penal del Enemigo a partir del Constitucionalismo Garantista y Dignatario", Revista Política Criminal № 8, 2009. 
En segundo lugar, designa a una teoría crítica del Derecho cuya misión consiste en denunciar la existencia de divergencias empíricas entre el ser y el deber ser de los ordenamientos jurídicos complejos, a raíz de los contrastes existentes entre sus modelos y sus prácticas concretas.

Y en tercer lugar, alude a una filosofía del Derecho -motivada por la desconfianza en el poder ${ }^{3}$ - en virtud de la cual se endosa al Derecho y al Estado el deber de justificación externa conforme a los bienes e intereses cuya tutela y garantía constituye precisamente su finalidad. ${ }^{4}$

El aporte que el garantismo hace al constitucionalismo contemporáneo y a los neoconstitucionalismos -en definitiva al Estado- consiste en la actitud que promueve en la ciencia jurídica: defiende una concepción del Estado como instrumento al servicio de la protección de los Derechos y del cientista jurídico no como mero observador acrítico de aquello que ocurre en los distintos estratos jurídicos, sino como sagaz perseguidor de los desajustes entre el deber ser y el ser del Derecho, entre el horizonte de valores propuesto por la Constitución y el comportamiento de los operadores jurídicos, empezando por el legislador que con frecuencia frustra o desatiende dicho horizonte. Empero, el garantismo no se satisface con la mera denuncia, sino que requiere además la búsqueda de soluciones mediante el empleo de las garantías actualmente disponibles en el propio ordenamiento jurídico o, si estas son insuficientes, el diseño de nuevas garantías que permitan colmar la laguna causada por la existencia de una norma constitucional insuficientemente garantizada. ${ }^{5}$

Sin embargo, aquella comprometida militancia que el garantismo promueve en los operadores jurídicos -si no se adoptan ciertos recaudos- puede devenir en el peor enemigo de los derechos fundamentales, entendidos éstos en palabras del mismo Ferrajoli como "La ley del más débil".

Justamente a aquello se refieren los profesores Salazar Ugarte (Investigador del Instituto de Investigaciones Jurídicas de la UNAM), Aguiló Regla (Catedrático de Filosofía del Derecho de la Universidad de Alicante) y Presno Linera (Titular de Derecho Constitucional de la Universidad de Oviedo) en las ponencias que presentaron en el seminario sobre Derecho y Jurisprudencia realizado a comienzos de 2009 en Madrid y organizado por la Fundación Coloquio Jurídico Europeo, que se contienen en el volumen que comentamos.

La ponencia de Pedro Salazar se recoge en un artículo titulado Dos versiones de un garantismo espurio en la Jurisprudencia Mexicana. El uso de aquel oscuro adjetivo proviene de lo que -a su juicio- es la irreflexiva aplicación del

${ }^{3}$ Ferrajol, Luigi, "Garantías", en Carbonell, Miguel, (Editor), Democracia y Garantísmo, Trotta, Madrid, 2008, p. 62.

${ }^{4}$ FerRajol, Luigi, Derecho y razón. Teoría del garantísmo penal, Trotta, Madrid, p. 853.

${ }^{5}$ Prieto Sanchís, Luis, Justicia constitucional y derechos fundamentales, Trotta, Madrid, 2003, p. 106. 
garantismo que practican algunos altos tribunales mexicanos. En efecto, el autor alza la voz ante polémicas sentencias de la Suprema Corte de Justicia y del Tribunal Electoral Federal. Cuestiona a la primera por proceder a un control de constitucionalidad en ausencia tanto de una norma de competencia que la habilite a efectuarlo como de disposiciones protegidas por cláusulas de intangibilidad.

Y denuncia al Tribunal Electoral Federal, primero, por declarar inaplicable un artículo de la Constitución Federal por estimarlo contrario a una disposición del Pacto de Derechos Civiles y Políticos -el cual previamente, en la misma resolución había sido ubicado por dicha magistratura en un rango normativo infraconstitucional, pero superior a la ley federal-e incompatible con lo dispuesto en la misma materia por la Constitución del Estado de Puebla. Y segundo, por fundamentar otra sentencia con un ejercicio de "control de constitucionalidad invertido" similar al del caso anterior, acogiendo la pretensión de un sujeto que gozaba de una posición social preferente y luego, en la misma sesión, rechazar una solicitud idéntica, interpuesta esta vez por un ciudadano de a pie.

En todos estos casos, subraya con impotencia Salazar, el sentenciador declara expresamente actuar de forma garantista.

Aquellos episodios -en su opinión- no harían otra cosa que confirmar algunas de las tesis que expone, especialmente: que en el funcionamiento actual de los sistemas jurídicos "se corre el riesgo de que los jueces obren sobre la base de un razonamiento moral abierto, que les hace sentir sin embargo, como si estuvieran aplicando Derecho. Y el problema es que no están preparados para esta tarea porque su razonamiento moral no pasa de ser vulgar" (p. 17).

Su mirada crítica hacia la aplicación espuria del garantismo -en todo casono debe ser confundida con una aversión ante aquél. Por el contrario, tiempo atrás Salazar ha confesado su admiración y afinidad por dicha teoría, al menos en su variante procedente del pensamiento ferrajoliano. ${ }^{6}$ Se trata, simplemente, de una sentida advertencia, pues "en los hechos, la importación de la teoría garantista puede resultar contraproducente en contextos en los que los operadores jurídicos -en particular los jueces- no están debidamente adiestrados para gestionar las implicaciones de dicho modelo o deciden utilizar su fuerza simbólica para aumentar el poder de los órganos jurisdiccionales" (p. 23).

Josep Aguiló Regla, por su parte, nos presenta una contraponencia destinada principalmente a analizar críticamente los planteamientos de Salazar. No obstante, su ejercicio termina por traspasar esa frontera. Así propone interesantes reflexiones bajo el epígrafe "Breviario de Teoría de la Constitución del Estado

${ }^{6}$ Salazar Ugarte, Pedro, "Los límites a la mayoría y la metáfora del contrato social en la teoría democrática de Luigi Ferrajoli", en Carbonel; Salazar, Garantismo, cit. nota n. 1, p. 430. 
constitucional". A riesgo de ser inexacto, podríamos decir que el razonamiento que sugiere es el siguiente: las aporías generadas por las relaciones dialécticas entre las distintas concepciones constitucionales (v. gr. Democracia - Derechos, Constitución como documento político - Constitución como documento jurídico, Soberanía de la Ley - Activismo Judicial) no tienen una solución adecuada en planteamientos estructurales, abstractos e institucionales.

Por último, Miguel Presno Linera cierra la edición con su ponencia titulada "El empleo espurio de las sentencias interpretativas para realizar cambios estructurales en el sistema constitucional". En ella ilustra la potencial influencia de las denominadas sentencias atípicas del Tribunal Constitucional español, por medio de tres casos en los cuales su empleo conduce a importantes cambios estructurales en el sistema, constatando - de paso- la necesaria revisión de la noción tradicional de legislador.

En síntesis, junto a las acertadas e interesantes reflexiones de los autores, en el presente libro subyace un Ilamado de atención a la academia. En ello reside su atractivo. Como lo ha señalado reiteradamente Santiago Sastre Ariza, en el contexto actual, el papel de la ciencia jurídica no debe reducirse a la mera descripción, sino a la denuncia de todo uso ilegítimo del poder. Ello implica desarrollar una labor pedagógica constante no sólo en las aulas, sino destinada también a todo operador jurídico, elaborando conceptos, criterios y categorías que permitan identificar y depurar el uso inapropiado del poder y el empleo espurio de teorías para justificarlo, sólo de esta forma es posible resistir a la irreductible aporía del ejercicio ilegítimo del poder, público o privado. 